\title{
Effects of HSP90 inhibitor 17-allylamino-17 -demethoxygeldanamycin (17-AAG) on NEU/HER2 overexpressing mammary tumours in MMTV-NEU-NT mice monitored by Magnetic Resonance Spectroscopy
}

Loreta M Rodrigues', Yuen-Li Chung ${ }^{2}$, Nada M S Al Saffarr', Swee Y Sharp ${ }^{3}$, Laura E Jackson², Udai Banerji', Marion Stubbs ${ }^{1}$, Martin O Leach², John R Griffiths ${ }^{1 *}$ and Paul Workman ${ }^{3}$

\begin{abstract}
Background: The importance of ERBB2/NEU/HER2 in the response of breast tumours to the heat shock protein 90 (HSP90) inhibitor 17-allylamino-17-demethoxygeldanamycin (17-AAG; tanespimycin) has been demonstrated in the clinic. ERBB2 is an oncoprotein client that is highly dependent on HSP90. This and other oncogenic client proteins (e.g. B-RAF, C-RAF, ALK and CDK4) are depleted by 17-AAG in both animal tumours and patients. Here we investigate by Magnetic Resonance Spectroscopy (MRS) the metabolic response of 17-AAG in spontaneous, NEU/HER2 driven mammary tumours in transgenic MMTV-NEU-NT mice and in cells isolated and cultured from these tumours.

Methods: Mammary tumours were monitored by ${ }^{31} \mathrm{P}$ MRS in vivo and in tumour extracts, comparing control and 17-AAG treated mice. A cell line derived from NEU/HER2 mammary tumours was also cultured and the effect of 17-AAG was measured by ${ }^{31} \mathrm{P}$ MRS in cell extracts. Molecular biomarkers were assessed by immunoblotting in extracts from cells and tumours. For comparison of tumour volume, metabolite concentrations and Western blot band intensities, two-tailed unpaired t-tests were used.

Results: The NEU/HER2 mammary tumours were very sensitive to 17-AAG and responded in a dose-dependent manner to 3 daily doses of 20, 40 and $80 \mathrm{mg} / \mathrm{kg}$ of 17-AAG, all of which caused significant regression. At the higher doses, ${ }^{31} \mathrm{P}$ MRS of tumour extracts showed significant decreases in phosphocholine (PC) and phosphoethanolamine (PE) whereas no significant changes were seen at the $20 \mathrm{mg} / \mathrm{kg}$ dose. Extracts of isolated cells cultured from the mammary carcinomas showed a significant decrease in viable cell number and total PME after 17-AAG treatment. Western blots confirmed the expected action of 17-AAG in inducing HSP72 and significantly depleting HSP90 client proteins, including NEU/HER2 both in tumours and in isolated cells.

Conclusions: The data demonstrate the high degree of sensitivity of this clinically relevant NEU/HER2-driven tumour model to HSP90 inhibition by 17-AAG, consistent with the clinical data, and suggest that the metabolic signature of choline phospholipids obtained by MRS could be useful both as a preclinical and clinical tool for investigating surrogate markers of response to treatment.
\end{abstract}

Keywords: Magnetic resonance spectroscopy, MMTV-NEU-NT tumours, ERBB2/ HER2/ NEU, HSP90, 17-AAG

\footnotetext{
* Correspondence: John.Griffiths@cancer.org.uk

${ }^{1}$ Cancer Research UK Cambridge Research Institute, Li Ka Shing Centre,

Robinson Way, Cambridge CB2 ORE, UK

Full list of author information is available at the end of the article
} 


\section{Background}

The novel anticancer drug 17-allylamino-17-demethoxygeldanamycin (17-AAG; tanespimycin), which inhibits the molecular chaperone HSP90, has shown activity against breast cancer in the clinic [1-3]. Regressions were seen only in patients with metastatic breast cancer that was positive for ERBB2/HER2, a very sensitive oncoprotein client of HSP90. The ERBB2 receptor tyrosine kinase, a member of the epidermal growth factor receptor (EGFR) family, is overexpressed in $20-30 \%$ of primary human breast cancers, and expression correlates with poor patient outcome [4]. ERBB2/HER2 is a target for both antibodybased therapy (as with trastuzumab) and tyrosine kinasebased inhibitors (as with lapatinib), but resistance is seen in the clinic [5]. ERBB2/HER2 is one of the most sensitive client proteins of HSP90 [6,7], and 17-AAG has been shown to cause depletion of ERBB2/HER2 leading to significant growth inhibition in ERBB2/HER2 overexpressing breast cancer cells and tumour xenografts [8], and more importantly to cause regression in trastuzumab-refractory ERBB2/HER2 positive breast cancer patients [1-3]. Data from Phase 2 trials have recently confirmed this impressive anti-tumour activity of 17-AAG and validated HSP90 as a therapeutic target for ERBB2/HER2-driven breast cancer [2].

17-AAG, a derivative of the naturally-occurring ansamycin antibiotic geldanamycin, is known to bind specifically to the ATP site in the $\mathrm{NH}_{2}$-terminal domain of the molecular chaperone HSP90 and inhibit its function [7,9]. As well as ERBB2, HSP90 is required for the correct conformation and function of many other oncogenic client proteins, including CDK4, C-RAF, B-RAF, AKT, MET, ALK, EGFR and p53 [10,11].

Several mutant oncoproteins are more dependent than their wild-type forms on HSP90 but ERBB2 is the most sensitive HSP90-dependent client protein identified to date $[11,12]$. Tumour cells contain HSP90 complexes in a more highly activated, high affinity conformation compared to normal cells, and it has been proposed that this might contribute to malignant progression [13]. HSP90 is therefore a key therapeutic target, since a drug that simultaneously inhibits several oncogenic signaling pathways is likely to be particularly effective $[7,11,12,14]$. Recent clinical experience indicates that HSP90 inhibitors are showing therapeutic activity in settings where they deplete sensitive HSP90 clients in tumour types that are addicted to those clients, with ERBB2-positive, trastuzumab-refractory breast cancer providing the best example [2,3]. Clinical development of HSP90 inhibitors is focusing heavily on these tumours and additional studies in mechanistically relevant preclinical models are warranted to support and inform the ongoing clinical work.

The development of transgenic mouse models that recapitulate the initial events of ERBB2-induced mammary tumourigenesis has played a key role in understanding the molecular basis of ERBB2-driven tumours [15]. NEU/HER2 is the rat homolog of human ERBB2 and in one transgenic mouse model, MMTV-NEU-NT, that expresses the activated mutant form of NEU under the transcriptional control of the MMTV promoter, the mice develop spontaneous tumours in the mammary gland [16]. This tumour model is particularly suited to studying the effects of 17-AAG since the tumours that arise are driven by the activated form of the NEU/HER2 oncogene and are addicted to it, just as ERBB2 amplified breast cancers in the clinic are driven by and addicted to the amplified ERBB2. The action of 17-AAG on HSP90 promotes the degradation of client proteins through the ubiquitin-proteasome pathway, and such a pleiotropic mechanism may induce complex metabolic effects that may vary from one tumour to another. In the discovery and in early clinical trials of HSP90 inhibitors, it will therefore be important to develop non-invasive monitoring methods that can distinguish these responses. Such methods could then be used in the clinic to select tumours that are likely to respond to treatment, with advantages over more invasive techniques [17-19].

Magnetic resonance spectroscopy (MRS) can be used non-invasively to study the biochemistry and physiology of tumours in vivo, and also ex vivo on extracts of either tumours or cells. ${ }^{31} \mathrm{P}$ MRS has been used to monitor growth and response to therapy both in animal tumour models and in patients [20-24]. Biomarkers for tissue bioenergetics, such as nucleotide triphosphate (NTP), inorganic phosphate $(\mathrm{Pi})$, and intracellular $\mathrm{pH}(\mathrm{pHi})$, as well as various phosphorus-containing phospholipid metabolites are readily observed with ${ }^{31} \mathrm{P}$-MRS. The phospholipid metabolites that provide information on membrane metabolism are the phosphomonoesters (PMEs) phosphocholine (PC) and phosphoethanolamine (PE), which are precursors of the phosphatidylcholine and phosphatidylethanolamine in biological membranes, and the phosphodiesters (PDEs) glycerophosphocholine (GPC) and glycerophosphoethanolamine (GPE), which are breakdown products of phosphatidylcholine and phosphatidylethanolamine. The pharmacodynamic actions of many anticancer drugs have been studied, and characteristic ${ }^{31} \mathrm{P}$ MRS signatures established (for a review see [25]). Since MRS changes induced by 17-AAG occur in parallel with the expected molecular marker changes, the MRS signatures have the potential to provide surrogate markers of treatment response [26-28]. We therefore set out to look at the MRS signature of the action of 17-AAG in spontaneous, mammary tumours in transgenic MMTV-NEU-NT mice where the tumors that arise are driven by the activated form of the NEU/ HER2 oncogene and are addicted to it, similar to ERBB2 amplified breast cancer in the clinic. 


\section{Materials and methods Materials}

17-AAG for the in vivo and in vitro study was either provided (dissolved in DMSO at $25 \mathrm{mg} / \mathrm{mL}$ ) by Dr. P. Ivy at the National Cancer Institute (Bethesda, MD) or purchased (powder form) from Alexus Biochemicals (Switzerland) and dissolved in DMSO at $25 \mathrm{mg} / \mathrm{mL}$. Dilutions to $2.5 \mathrm{mg} /$ $\mathrm{mL}$ were made in a vehicle of egg phospholipid supplied by Dr. P. Ivy. Dulbecco's Modified Eagle Medium (DMEM), penicillin, and streptomycin were purchased from Life Technologies (Paisley, UK) and fetal calf serum (FCS) from PAA labs Ltd. (Somerset, UK). Hypnorm was purchased from Jansen Pharmaceuticals (Buckinghamshire, UK), and Hypnovel was purchased from Roche (Welwyn Garden City, UK). Perchloric acid (PCA) and potassium hydroxide were purchased from Merck (Poole, UK). Sodium 3-trimethylsilyl-2,2,3,3-tetra-deuteropropionate (TSP) was purchased from Goss Scientific Instruments Ltd, UK. All other chemicals were purchased from Sigma (Poole, UK).

\section{MMTV-NEU-NT tumour model}

Female transgenic mice expressing the mutant activated form of rat NEU (NEU-NT) under transcriptional control of the MMTV promoter (MMTV-NEU-NT mice) were purchased from Charles River, UK. The mating strain is the $\mathrm{FVB} / \mathrm{N}$ mouse and multiple tumours involving the entire mammary epithelium arise synchronously in the mammary gland area [16] between 18-20 weeks of age in $35-50 \%$ of the mice.

Mice were maintained under strict inbreeding conditions; health was monitored every 3 months and the presence of the Neu transgene was routinely checked by PCR on tail DNA. Animals were anesthetized with $8 \mathrm{~mL} /$ kg of a Hypnorm: Hypnovel: water (1:1:2) mixture. All experiments were performed in accordance with the UK Home Office Animals Scientific Procedures Act 1986 and national UK Coordinating Committee on Cancer Research's (UKCCCR) guidelines [29]. All measures were taken to minimize any pain or discomfort to the animals.

Tumour volume was calculated using the formula $(\pi / 6)$ $(d 1 \cdot d 2 \cdot d 3)$ where $d 1, d 2$ and $d 3$ are the three orthogonal diameters measured by callipers to derive an ellipsoidal volume.

Several cohorts of mice were used: of the treated cohorts, one received $20 \mathrm{mg} / \mathrm{kg} 17-\mathrm{AAG}$ i.p., a second received $40 \mathrm{mg} / \mathrm{kg}$ and a third received $80 \mathrm{mg} / \mathrm{kg}$, once a day for 3 days. The fourth control cohort received vehicle (egg phospholipid in 10\% DMSO), once a day for 3 days. In vivo MRS was performed on day 0 and day 4 , and tumours were freeze-clamped on day 4. Western blot analysis was performed on part of the tumour tissue, and ${ }^{31} \mathrm{P}$ and ${ }^{1} \mathrm{H}$ MRS were performed on acid extracts of tumour tissue. In a fifth cohort, as part of a regrowth study, the mice received $40 \mathrm{mg} / \mathrm{kg} 17-\mathrm{AAG}$ once a day for 3 days and the tumours were monitored up to 14 days after the end of treatment.

\section{In vivo MRS}

In vivo magnetic resonance experiments were performed on a Varian Unity Inova 4.7T spectrometer. During the MR experiments, all animals were covered with a warm water blanket and core temperature maintained at $37^{\circ} \mathrm{C}$.

For ${ }^{31} \mathrm{P} \mathrm{MRS}$, the volume of interest selected from a ${ }^{1} \mathrm{H}$ image included as much of the tumour as possible and avoided the underlying body wall. ISIS (imageselected in vivo spectroscopy) [30] localized spectra of tumours were acquired using a $10 \mathrm{~mm}$, two-turn surface coil, TR of $3 \mathrm{~s}$ and 240 acquisitions. Spectra were acquired prior to treatment and at day 4 in the cohorts that received 3 doses, at $24 \mathrm{hr}$ in the single dose cohort and at days 4, 8, 11 and 18 in the regrowth cohort. Spectra were quantitated using VARPRO, a time-domain non-linear least squares method [31]. The data were fitted assuming contributions from phosphomonoesters (PME), phosphodiesters (PDE), inorganic phosphate $\left(\mathrm{P}_{\mathrm{i}}\right)$, phosphocreatine $(\mathrm{PCr})$, and the $\alpha-, \beta$ - and $\gamma$-nucleoside triphosphate (NTP) resonances.

\section{High resolution ${ }^{1} \mathrm{H}$ and ${ }^{31} \mathrm{P}$ MRS of tumour extracts}

Part of the freeze-clamped tumour was extracted with 4 volumes of $6 \%$ PCA. The neutralized extracts were freezedried, reconstituted in deuterium oxide and placed in $5 \mathrm{~mm}$ NMR tubes. MR spectra were acquired at room temperature on a $500 \mathrm{MHz}$ Bruker spectrometer (Bruker Biospin, Coventry, UK).

For ${ }^{1} \mathrm{H}$ MRS, the water resonance was suppressed by using gated irradiation centered on the water frequency. TSP (50ul, 5mM) was used for chemical shift calibration and quantitation.

For ${ }^{31} \mathrm{P}$ MRS, metal ions were chelated by addition of EDTA (50ul, 60mM) and methylene diphosphonic acid (MDP, 50ul, 5mM) was added to each sample for chemical shift calibration and quantitation.

Metabolite concentrations were determined by peak integration, normalized to the peak integral of the respective internal standard (TSP for ${ }^{1} \mathrm{H}$ and MDP for ${ }^{31} \mathrm{P}$ MRS).

\section{Cell culture and drug treatment}

A cell line of ERBB2/HER2-induced mammary carcinoma cells was established from a tumour mass excised from an MMTV-NEU-NT mouse $[15,16]$. The tumour cells were cultured in DMEM supplemented with $10 \% \mathrm{FCS}, 100 \mathrm{U} / \mathrm{mL}$ penicillin and $100 \mu \mathrm{g} / \mathrm{mL}$ streptomycin at $37^{\circ} \mathrm{C}$ in $5 \% \mathrm{CO}_{2}$. Cell growth inhibition (96-hours) for these tumour cells, with seeding density of $1 \times 10^{3}$ in $200 \mu \mathrm{L}$ using 96 well plates, was measured by sulforhodamine B (SRB) 
assay to assess $\mathrm{GI}_{50}$ [32]. Cells were treated with 17-AAG at pharmacologically active concentrations corresponding to $5 \mathrm{x} \mathrm{GI}_{50}(1.12 \mu \mathrm{M})$ for 24 -hours at $37^{\circ} \mathrm{C}$. The cells were collected by scraping, and viability was checked by the trypan blue exclusion assay [26]. The effect of treatment on viable cell number was monitored by counting the number of attached cells in the treated flask and comparing that with the number of attached cells in the control flask.

\section{Cell cycle analysis}

Cell cycle analysis of attached control and treated cells was performed on cells $\left(1 \times 10^{6}\right)$ fixed in $70 \%$ ethanol, treated with $100 \mu \mathrm{g} / \mathrm{mL}$ RNase A in citrate-buffered saline for 30 minutes at $37^{\circ} \mathrm{C}$ and stained with $4 \mu \mathrm{g} / \mathrm{mL}$ propidium iodide [33]. Samples were analysed on a BD LSR II (San Jose, CA, USA) on a "low" flow rate and excited using a $488 \mathrm{~nm}$ laser beam, fluorescent light collected at $610 / 20 \mathrm{~nm}$ on a linear scale for the cell cycle analysis. Concurrently data were collected at 660/20 nm on a log scale to assess samples for endoreduplication. The flow cytometry data were analyzed and quantified using the WinMDI and Cylchred softwares (University of Wales College of Medicine, Cardiff, UK).

\section{High resolution ${ }^{31} \mathrm{P}$-MRS of cultured cell extracts}

$5 \times 10^{7}$ cells, approximately in log phase, were extracted from cell culture as previously described [34,35]. The freeze-dried extracts were resuspended in $\mathrm{D}_{2} \mathrm{O}$ with 10mM EDTA (pH 8.2).

${ }^{1} \mathrm{H}$-decoupled ${ }^{31} \mathrm{P}$-MRS spectra were acquired at room temperature on a $500 \mathrm{MHz}$ Bruker spectrometer (Bruker Biospin, Coventry, UK) using a $30^{\circ}$ flip angle, a 1 s relaxation delay, spectral width of $100 \mathrm{ppm}$, and $32 \mathrm{~K}$ data points. Metabolite contents were determined by integration, normalized relative to the peak integral of an internal reference of MDP $(60 \mu \mathrm{L}, 1 \mathrm{mM})$, and corrected for signal intensity saturation and the number of cells extracted per sample.

\section{Western blot analysis}

Standard Western blotting procedures were performed as described previously [36]. Briefly, cells were trypsinized, washed with PBS and lysed at $4{ }^{\circ} \mathrm{C}$ in lysis buffer (Cell Signalling, Hertfordshire, UK) and protease inhibitor cocktail (Roche diagnostics, Mannheim, Germany). Protein concentrations were determined by the BIO-RAD assay method and bovine serum albumin as a standard. Antibody binding was identified with horseradish peroxidaselabeled secondary antibodies combined with enhanced chemiluminescence reagents (Amersham, Bucks, UK) and autoradiography.

Freeze-clamped tumours were lysed in $1 \mathrm{ml}$ of lysis buffer (0.1\% Nonidet P-40, 50mM HEPES (pH 7.4), 250mM NaCl, $1 \mathrm{mM}$ phenylmethylsulfonyl fluoride, $10 \mathrm{ug} / \mathrm{ml}$ aprotonin,
20uM leupeptin, 1mM dithiothreitol, 1mM EDTA, 1mM $\mathrm{NaF}, 10 \mathrm{mM} \beta$-glycerophosphate and $0.1 \mathrm{mM}$ orthovanadate), protein concentration determined by the BCA protein assay (Thermo Scientific Pierce) and Western blotting procedures were followed as above.

Antibodies used were HSP72 (SPA 810; Stressgen, Canada), B-RAF (SC5284; Santa Cruz Biotechnology, Santa Cruz, CA, USA), C-RAF (SC133; Santa Cruz Biotechnology, Santa Cruz, CA, USA), CDK4 (SC260; Santa Cruz Biotechnology), p-NEU (2247; Cell Signaling Technology), NEU/HER2 (SC284; Santa Cruz Biotechnology), and also glyceraldehyde-3-phosphate dehydrogenase (GAPDH; MAB374; Chemicon, Hampshire, UK) as a loading control.

Images of the blots of solid tumor and cell extracts were scanned on a ImageScanner III (GE HealthCare) using Labscan software, and bands were quantified by densitometry using the ImageQuant TL software.

\section{Statistical analysis}

The tumour cell data, solid tumour and tumour extract data are presented as the mean \pm SEM, $n=3-6$. For comparison of metabolite concentrations and tumour volumes, two-tailed unpaired $\mathrm{t}$ tests were used, and a $\mathrm{p}$ value of $<0.05$ was considered to be statistically significant.

\section{Results}

\section{Dose-dependent effects of 17-AAG on tumour volume}

The MMTV-NEU-NT mice developed multiple tumours associated with the mammary gland between 18-20 weeks of age. The tumour volumes at day 0 , the day preceding the first dose of treatment, were $0.59 \pm 0.08 \mathrm{~cm}^{3}$ $(\mathrm{n}=11), 0.67 \pm 0.07 \mathrm{~cm}^{3}(\mathrm{n}=11), 0.67 \pm 0.08 \mathrm{~cm}^{3}(\mathrm{n}=10)$, and $0.61 \pm 0.12 \mathrm{~cm}^{3}(\mathrm{n}=6)$ for the control 20,40 and $80 \mathrm{mg} / \mathrm{kg}$ cohorts respectively.

Tumours in the control mice (treated with vehicle only) had a doubling time of $12 \pm 2$ days $(n=6)$ and grew to $128 \pm 6 \%$ of pre-treatment volume after 4 days, while the tumours treated with 3 daily doses of 17-AAG at $20 \mathrm{mg} / \mathrm{kg}, 40 \mathrm{mg} / \mathrm{kg}$ and $80 \mathrm{mg} / \mathrm{kg}$ regressed to $88 \pm 3 \%$ $(\mathrm{p}<0.003), \quad 67 \pm 6 \% \quad(\mathrm{p}<0.003)$ and $42 \pm 7 \%$ $(\mathrm{p}<0.0005)$ respectively (compared with pre-treatment volume on day 0 ) by day 4 . When the tumour volumes at day 4 post-treatment were compared to untreated tumour volumes at day 4 , there were highly significant differences $(p<0.0002)$ at all doses (Table 1$)$. There were significant differences in tumour volumes between the $40 \mathrm{mg}$ and $80 \mathrm{mg} / \mathrm{kg}$ cohorts $(\mathrm{p}<0.03)$ and between the $40 \mathrm{mg}$ and $20 \mathrm{mg} / \mathrm{kg}$ cohort $(\mathrm{p}<0.02)$. These results show that the NEU-NT tumours are very sensitive to treatment with 17-AAG and demonstrate dosedependence of the therapeutic effect. The responsiveness is consistent with the results observed in a clinical study 
Table 1 Effect of 17-AAG on tumour volume

\begin{tabular}{lcccc}
\hline & $\begin{array}{c}\text { Tumour } \\
\text { volume } \\
\text { (\% of day 0) } \\
\text { at day 4 (N) }\end{array}$ & $\begin{array}{c}\text { P compared } \\
\text { to day 0 }\end{array}$ & $\begin{array}{c}\text { Tumour } \\
\text { volume } \\
\text { \% of control) } \\
\text { at day 4) }\end{array}$ & $\begin{array}{c}\text { P compared } \\
\text { to Control at } \\
\text { day 4 }\end{array}$ \\
\hline Control & $128.4 \pm 5.9(11)$ & 0.0007 & & \\
\hline $\begin{array}{c}17-\mathrm{AAG} \\
(20 \mathrm{mg} / \mathrm{kg})\end{array}$ & $88.5 \pm 2.9(11)$ & 0.003 & $68.9 \%$ & $<0.0001$ \\
\hline $\begin{array}{l}17-\mathrm{AAG} \\
(40 \mathrm{mg} / \mathrm{kg})\end{array}$ & $67.0 \pm 3.6(10)$ & $<0.0001$ & $52.2 \%$ & $<0.0001$ \\
\hline $\begin{array}{c}17-\mathrm{AAG} \\
(80 \mathrm{mg} / \mathrm{kg})\end{array}$ & $42.1 \pm 7(6)$ & 0.0004 & $32.8 \%$ & $<0.0001$ \\
\hline
\end{tabular}

Effect of 3 daily doses of $17-A A G(20 \mathrm{mg} / \mathrm{kg}, 40 \mathrm{mg} / \mathrm{kg}, 80 \mathrm{mg} / \mathrm{kg})$ or vehicle only (control) on tumour volume in MMTV-NEU-NT transgenic mice. Tumour volume expressed as a $\%$ of day 0 (column 2), p values: day 4 vs day 0 . Tumour volume also expressed as a \% of control cohort at day 4 (column 4), p values: treated day 4 vs control day 4 . Mean tumour volume at day 0 of the 4 cohorts was $0.59 \pm 0.08 \mathrm{~cm}^{3}$ (control), $0.67 \pm 0.07 \mathrm{~cm}^{3}(20 \mathrm{mg} / \mathrm{kg}), 0.67 \pm 0.08$ $\mathrm{cm}^{3}(40 \mathrm{mg} / \mathrm{kg})$ and $0.61 \pm 0.12 \mathrm{~cm}^{3}(80 \mathrm{mg} / \mathrm{kg})$. Data are presented as the mean \pm SEM.

of trastuzumab-refractory HER2-positive metastatic breast cancer using 17-AAG in combination with trastuzumab $[1,2]$.

In one cohort of mice $(n=4)$, where the animals were not sacrificed immediately after treatment (3 daily doses of $40 \mathrm{mg} / \mathrm{kg} 17-\mathrm{AAG}$ ), the tumours subsequently regrew at the original rate after the end of treatment (Figure 1).

Effects of 17-AAG on molecular biomarkers in MMTVNEU-NT tumours

HSP72 induction is known to be a sensitive indicator of HSP90 inhibition and is used alongside client protein depletion as a validated biomarker signature of HSP90 inhibition [37]. Western blots for HSP72, NEU/HER2,

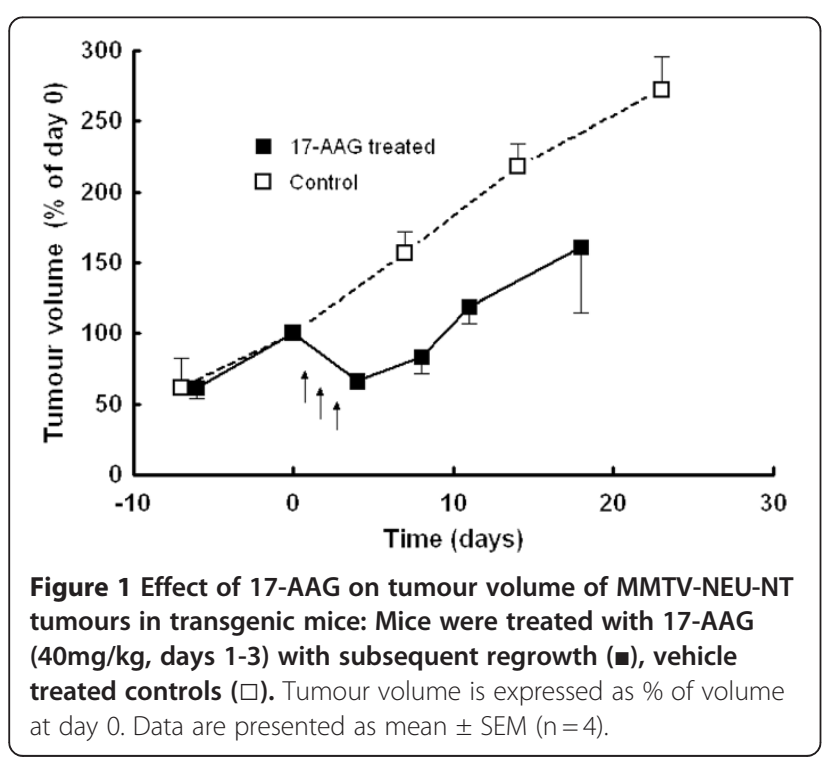

C-RAF and CDK4 were carried out on tumours from a cohort of 3 control mice and 3 mice treated with $40 \mathrm{mg} / \mathrm{kg}$ of 17-AAG for 3 days, where tumours were excised 24 hours after the last dose. The expected mechanism-based increase in HSP72 expression [37,38] was observed in all 3 treated tumours, and a decrease in the expression of NEU/ HER2, C-RAF and CDK4 was seen in 2 out of 3 tumours (Figure 2). The intensity of each protein band was determined relative to GAPDH. The mean normalized band intensity of NEU/HER2 decreased from 3.64 \pm 0.06 to $1.86 \pm 0.37(\mathrm{p}=0.009)$; C-RAF decreased from $3.01 \pm 0.04$ to $1.47 \pm 0.29(\mathrm{p}=0.006)$; HSP72 increased from zero to $3.12 \pm 0.25 \quad(\mathrm{p}=0.0002) ;$ and CDK4 decreased from $2.1 \pm 0.07$ to $1.22 \pm 0.1, \quad(p=0.002)$. Extracts of tumours from the $20 \mathrm{mg} / \mathrm{kg}$ cohort, taken $8 \mathrm{hrs}$ after the third dose, also showed consistent increases in HSP72 in all tumours and decreases in the expression of NEU/HER2 and phospho-NEU/HER2, C-RAF and CDK4, in 4 out of 6 tumours The mean band intensity, relative to GAPDH, of NEU/HER2 decreased from $1.09 \pm 0.02$ to $0.67 \pm 0.14$ ( $\mathrm{p}=0.03$ ); phospho-NEU/HER2 decreased from $0.58 \pm 0.11$ to $0.12 \pm 0.11(\mathrm{p}=0.03)$; C-RAF decreased from $0.21 \pm 0.05$ to $0.04 \pm 0.02(\mathrm{p}=0.04)$; CDK4 decreased from $0.23 \pm 0.04$ to $0.05 \pm 0.03 \quad(\mathrm{p}=0.02)$; and HSP72 increased from zero (undetectable) to $0.35 \pm 0.1 \quad(\mathrm{p}=0.02)$. Data are expressed as mean \pm sem, $\mathrm{n}=3$ for control tumours and

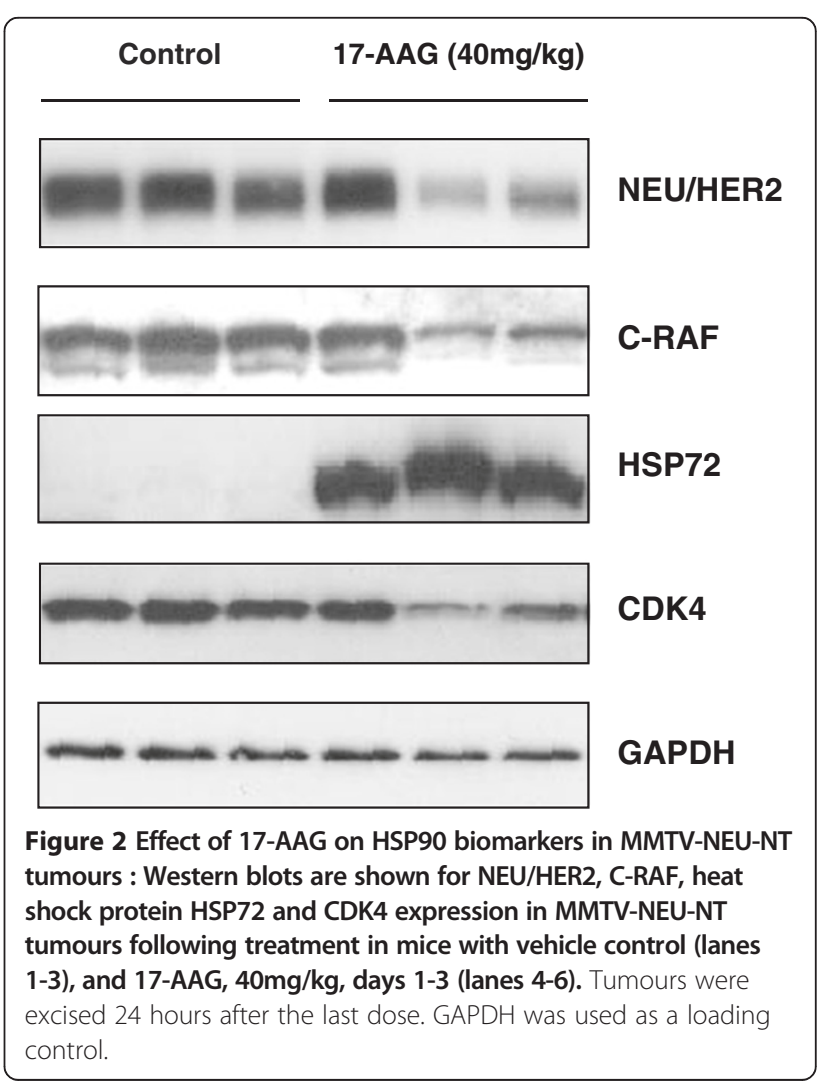


$\mathrm{n}=6$ for treated tumours. Taken together, these results show that 17-AAG caused a significant depletion of HSP90 client proteins, including NEU/HER2 in the MMTV-NEUNT tumour model at $20 \mathrm{mg} / \mathrm{kg}$ and $40 \mathrm{mg} / \mathrm{kg}$.

Effects of 17-AAG on PC and PE levels in MMTV-NEU-NT tumours measured by high resolution ${ }^{1} \mathrm{H}$ and ${ }^{31} \mathrm{P}$ MRS in tumour extracts

${ }^{31} \mathrm{P}$ MRS of extracts allows better resolution of the signals than spectra acquired from in vivo tissue. Spectra of extracts of tumours from mice that had received 3 daily doses of 17-AAG were acquired, and individual phospholipid metabolites, i.e. PC, PE, GPC and GPE, were observed. Tumours from mice treated with 3 doses of $80 \mathrm{mg} / \mathrm{kg} 17-\mathrm{AAG}$ showed decreases in PE $(\mathrm{p}=0.01)$, $P C(p=0.06)$ and $[P E+P C](p=0.001)$. At the $40 \mathrm{mg} / \mathrm{kg}$ dose the sum of $[\mathrm{PE}+\mathrm{PC}]$ was significantly lower (Figure 3) when compared with vehicle-treated controls $(\mathrm{p}=0.05)$. GPC and GPE levels were not significantly different at any of the 17-AAG dose levels when compared with vehicle-treated controls (Figure 3 ). ${ }^{1} \mathrm{H}$ MRS of the extracts confirmed a significant decrease in $\mathrm{PC}$ in a cohort of tumours $24 \mathrm{hrs}$ after treatment with $40 \mathrm{mg} / \mathrm{kg}$ 17-AAG, but no other significant changes were observed (data not shown).

\section{Effects of 17-AAG on PME levels in MMTV-NEU-NT tumours in vivo measured by ${ }^{31} \mathrm{P}$ MRS}

The metabolic response signature was also assessed as a potential non-invasive in vivo biomarker of HSP90 inhibition [26] pre and post 3 days of $40 \mathrm{mg} / \mathrm{kg} 17-\mathrm{AAG}$ treatment (see Figure 4). However, it was technically difficult to obtain spectra with a good signal to noise ratio at the $80 \mathrm{mg} / \mathrm{kg}$ dose due to the marked tumour regression caused by the treatment (Table 1). This technical difficulty has been noted in other MRS experiments in drugsensitive, rapidly regressing tumours [39]. No significant changes were noted in PME/Total P, PME/NTP, NTP/Pi ratios or intracellular $\mathrm{pH}$ in tumours pre- and post 17 AAG treatment at either the $20 \mathrm{mg} / \mathrm{kg}$ or $40 \mathrm{mg} / \mathrm{kg}$ dose (for 3 days) nor were there any significant changes in these ratios in the vehicle-treated controls.

\section{Effects of 17-AAG-treatment in cultured cells isolated from MMTV-NEU-NT tumours}

The effects of 17-AAG on the MMTV-NEU-NT tumour extracts measured by ${ }^{31} \mathrm{P}$ MRS were opposite to those seen previously in HT29 human colon tumours [26]; significant decreases $(\mathrm{p} \leq 0.05)$ in the phospholipid metabolites PC and PE were observed in the MMTVNEU-NT tumours, in contrast to significant increases in $\mathrm{PC}$ and PE $(\mathrm{p} \leq 0.05)$ that had previously been seen in HT29 colon tumours. However, significant regression $(\mathrm{p}<0.005)$ was seen at the 80,40 and $20 \mathrm{mg} / \mathrm{kg}$ doses in the MMTV-NEU-NT tumours compared to the tumour stasis that had previously been observed in the HT29 colon tumours, even at $80 \mathrm{mg} / \mathrm{kg}$. To investigate whether these differences were characteristic of the MMTVNEU-NT tumours at the cellular level, we isolated and cultured cells from the MMTV-NEU-NT tumours. These cultured cells were then treated for 24 hours with 17-AAG at pharmacologically active concentrations corresponding to $5 \times \mathrm{GI}_{50}(1.12 \mu \mathrm{M})$ as defined using the 96 hours SRB assay. The number of 17-AAG treated

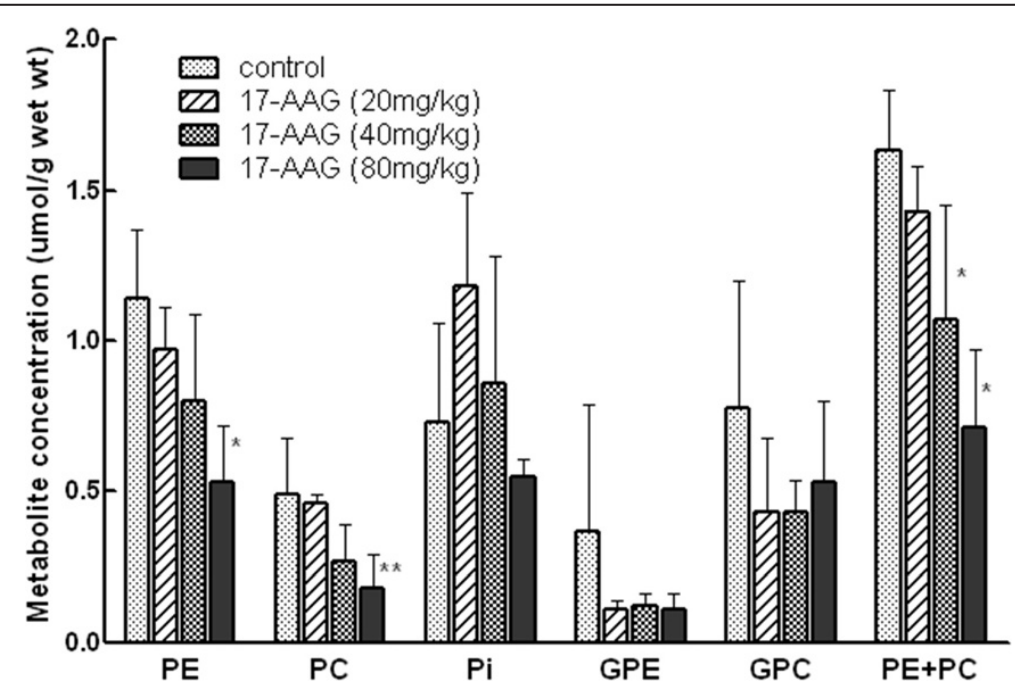

Figure 3 Effect of 17-AAG on phospholipid related metabolites and Pi by ${ }^{31} \mathrm{P}$ MRS in extracts of MMTV-NEU-NT tumors: 3 daily doses of 17-AAG $(\mathbf{2 0}, \mathbf{4 0}, \mathbf{8 0} \mathbf{~ m g} / \mathbf{k g})$ or vehicle only (control) and tumours sampled at $\mathbf{2 4} \mathbf{~ h r}$ post $\mathbf{3}^{\text {rd }}$ dose. Data are expressed as mean $\pm S E M$., $n=3$ to $6,{ }^{* *} p<0.05,{ }^{*} p=0.06$ when compared to controls. Phosphoethanolamine (PE), phosphocholine (PC), inorganic phosphate (Pi), glycerophosphoethanolamine (GPE), glycerophosphocholine (GPC). 


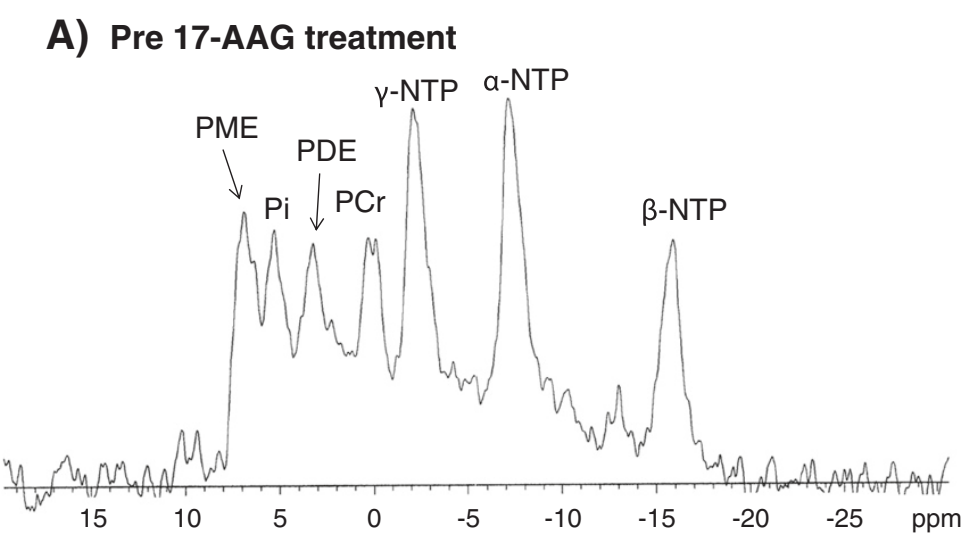

B) Post 17-AAG treatment

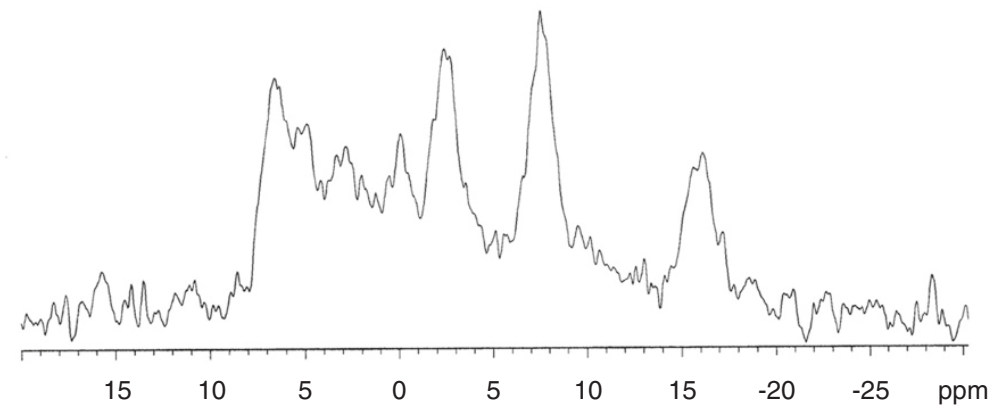

Figure 4 Effect of 17-AAG on in vivo ${ }^{31} \mathrm{P}$ MR spectra of MMTV-NEU-NT tumours in transgenic mice: 3 daily doses of 40mg/kg 17-AAG: A) pre-treatment with 17-AAG, B) $24 \mathrm{hrs}$ after 3rd dose of 17-AAG.

cells per flask as a $\%$ of control showed a statistically significant reduction to $65.6 \pm 6.1 \%(\mathrm{n}=6, \mathrm{P}<0.004)$, consistent with decreased proliferation.

The MMTV-NEU-NT tumour cell line continued to overexpress NEU/HER2 in cell culture and this expression was largely abolished by $17-\mathrm{AAG}$ treatment, as shown by western blotting (Figure $5 \mathrm{~A}$ ). The mean normalized band intensity of NEU/HER2 decreased from $0.34 \pm 0.04$ to $0.05 \pm 0.005(\mathrm{p}<0.001)$. There were also significant decreases in the normalized band intensity of C-RAF, from $0.53 \pm 0.11$ to $0.21 \pm 0.07$ ( $\mathrm{p}<0.05$ ), and of cyclin D1, from $1.21 \pm 0.1$ to $0.85 \pm 0.04(\mathrm{p}<0.03)$. Normalized intensity changes of B-RAF $(1.96 \pm 0.16$ to $1.84 \pm 0.12)$ and CDK4 $(0.88 \pm 0.1$ to $0.79 \pm 0.05)$ were not significant. Treatment with $17-\mathrm{AAG}$ also induced HSP72 expression, the normalized band intensity of which increased from $0.35 \pm 0.04$ to $0.97 \pm 0.05 \quad(\mathrm{p}<0.0001)$. Quantitation of band intensity is expressed relative to GAPDH, mean \pm sem, $n=5$ (Figure $5 \mathrm{~A}$ ). These results provide molecular evidence that HSP90 was inhibited in the 17-AAG-treated cultured mammary tumour cells, including marked depletion of NEU/HER2.

To further characterize the cellular effects of 17-AAG on cultured MMTV-NEU-NT mammary tumour cells, cell cycle distribution following 17-AAG treatment was determined by flow cytometry on the attached cell population.
Exposure to 17-AAG induced a significant accumulation in the G1 phase population from $50.9 \pm 1.4 \%$ to $72.2 \pm 0.8 \%$ $(\mathrm{n}=6, \mathrm{p}<0.0001)$ and a decrease in the $\mathrm{S}$ phase population from $40.3 \pm 0.8 \%$ to $19.0 \pm 0.9 \%$ ( $<<0.0000001)$.

Effects of 17-AAG on phospholipid metabolites in extracts of cultured cells isolated from MMTV-NEU-NT tumours measured by high resolution ${ }^{31} \mathrm{P}$ MRS

${ }^{31} \mathrm{P}-\mathrm{MR}$ spectra of extracts of control and 17-AAG-treated (24hrs) mammary carcinoma cells cultured from MMTVNEU-NT mouse tumours are shown in Figure 5B. Detailed analysis of the spectra demonstrated that 17 AAG treatment led to a statistically significant decrease in PME $(76.8 \pm 4.6 \%, \mathrm{p}=0.006)$. Of the signal contributing to the total PME, the largest proportion (83\%) came from PC which also showed a significant decrease $(66.7 \pm 6.3 \%$, $\mathrm{P}=0.005$ ). However, a small but significant increase was seen in the PE contribution $(132.8 \pm 11.3 \%, \mathrm{P}<0.05)$. GPE $(200.8 \pm 46.6 \%)$ and GPC $(204.4 \pm 57.2 \%)$ both showed increases but did not reach significance $(\mathrm{p}=0.11$ and 0.16 respectively) (Figure $5 \mathrm{C}$ ). The ratio of $\mathrm{PC} / \mathrm{GPC}$ also showed a significant decrease $(46.7 \pm 10.9 \%, \mathrm{p}<0.01)$.

\section{Discussion}

The transgenic MMTV-NEU-NT mouse is a suitable and relevant model for ERBB2-driven human breast 




cancer [15]. It has been used in the present study to investigate effects of inhibition of the molecular chaperone HSP90, both because ERBB2 is one of the client proteins most sensitive to HSP90 inhibition and because of the clinical activity seen with 17-AAG in ERBB2-positive, trastuzumab-refractory breast cancer patients $[1,2]$. The results reported in this paper show that the MMTVNEU-NT tumours are very sensitive to 17-AAG, confirming that NEU/HER2 is a prime target downstream of 17-AAG. Dose-dependent regression of the MMTV-
NEU-NT tumours was seen at doses of 20,40 and $80 \mathrm{mg} / \mathrm{kg}$ (Table 1) whereas the drug has been found to be cytostatic in human tumour xenografts, including the HT29 colon tumour that we studied previously [26]. Tumour regrowth occurred soon after the treatment ceased (Figure 1). This suggests that when treatment is withdrawn, NEU/HER2 is able to recover its potent oncogenic activity. Most importantly, the regressions seen in the transgenic model recapitulated the regressions seen in the ERBB2-positive breast cancer patients. 
The molecular effects of $20 \mathrm{mg} / \mathrm{kg}$ or $40 \mathrm{mg} / \mathrm{kg} 17$ AAG on the transgenic MMTV-NEU-NT (Figure 2) tumours included the induction of the co-chaperone HSP72 and depletion of client proteins NEU/HER2, CRAF and CDK4 (Figure 2). These results are consistent with the well-established molecular signature of HSP90 inhibitors $[7,10,11,37,38,40]$. Similar molecular changes, in addition to down-regulation of cyclin D1, were observed in isolated, cultured NEU/HER2 mammary cells following treatment with 17-AAG (Figure 5A).

No significant changes were seen in vivo by ${ }^{31} \mathrm{P}$ MRS, possibly because the tumours regressed so rapidly that the signal/noise from the treated tumours was too low for effects to be quantifiable. Studies performed on tumour extracts at higher resolution ex vivo, however, did give statistically significant results. Increasing doses of 17-AAG caused a progressive fall in the mean concentrations of $\mathrm{PE}$ and PC measured in tumour extracts (Figure 3). Interestingly, these were only significantly different at the higher doses, when substantial tumour regression had taken place. Extracts of cells cultured from the tumours also showed a significant decrease in PC and total PME $(\mathrm{PC}+\mathrm{PE})$. However the PE component (17\%) of the PME peak showed a significant increase when expressed as a \% of control cells. PC, a cytosolic intermediate for the biosynthesis of phosphatidylcholine and a major phospholipid component of human cellular membranes, can be a useful indicator of tumour progression and therapeutic response [41]. In several tumour types that have regressed after treatment, a decrease in PC has been seen [41], similar to the changes observed in the extracts of both MMTV-NEU-NT tumours in vivo and cells cultured from these tumours, in this study. However in other cell and tumour types, an increase has been seen (reviewed in [25-27]) and more recently, PC was unchanged in a melanoma cell line [42] when treated with 17-AAG. The MRS metabolic response signature in solid tumour extracts showed some differences to that observed in the cultured mammary tumour cells - i.e. a decrease in $\mathrm{PE}$ in solid tumours in contrast to an increase in PE in the cultured cells. However, the tumours in vivo, unlike the isolated cultured tumour cells, would of course contain many other cells including stromal cells and macrophages, which may well confound the metabolic signature. Although no gross histological differences were seen between the treated and untreated tumours, it is possible that factors associated with regression (which also made it technically difficult to obtain good MR spectra in vivo), contributed significantly to the metabolic signature measured by MRS.

The fall in PE and PC in response to 17-AAG, observed in solid tumour extracts in the present study (Figure 3) should be considered in the context of the tumour- and drug-dependent PE and PC responses that have been obtained with ${ }^{31} \mathrm{P}$ MRS in anticancer drug studies on tumour models in rodents. A recent review [25] cites ${ }^{31} \mathrm{P}$
MRS studies in which PE and/or PC increased in response to chemotherapy with five anticancer drugs: 5-fluorouracil, ifosfamide, LAQ824 and SAHA (histone deacetylase inhibitors) and 17-AAG. In contrast, ten drugs induced falls in PC and/or PE: cyclophosphamide, docetaxel, the choline kinase inhibitor MN58b, the vascular disrupting agent ZD6126, the HIF-1 $\alpha$ inhibitor PX478, the PI3 kinase inhibitors LY294002 and wortmannin, the MAPK inhibitor U0126, and orlistate, a fatty acid synthase inhibitor. This suggests that the PE and PC responses are drug-dependent and perhaps also tumour model-dependent.

All the above studies, including our previous one on 17AAG [26] were performed on subcutaneously implanted tumour models and/or on isolated cells. To our knowledge, the present study is the first in which ${ }^{31} \mathrm{P}$ MRS has been used to monitor the effect of an HSP90 inhibitor on spontaneous transgenic mouse tumours that arose in their true tissue of origin, in this case the mammary gland. Spontaneous tumours in genetically-engineered animals have a number of potential advantages over subcutaneously implanted tumours for testing anticancer drugs [43]. In particular, their histology and vasculature in many cases more closely resemble those of tumours in patients [44]. Since MR spectra are derived from both the tumour cells and the host stroma, that aspect of the model is important; indeed the metabolic state of the tumour cells themselves is strongly influenced by factors such as blood supply, which is often less adequate in implanted tumours than in spontaneous tumours [45], and by the host inflammatory response.

The ${ }^{31} \mathrm{P}$ MRS response observed in human tumours responding to chemotherapy in vivo in the clinic is often a decrease in PE and PC (usually observed as a combined PME peak). Negendank [41] performed a meta-analysis on data from human tumours treated with chemotherapy from eight studies and found that 26/34 tumours showed a decreased PME peak, with 8 unchanged, whereas 4/7 non-responders showed increased PME peaks with 3 unchanged [41]. It is interesting, therefore, that the spontaneous NEU-NT/HER2 overexpressing mammary tumours studied here also showed decreased $\mathrm{PE}$ and $\mathrm{PC}$ in response to 17-AAG. However, in view of the broad spectrum and apparent drug-specificity of the PE and PC results reported from previous studies with implanted tumours, it will be necessary to wait for further results from other anticancer drug studies on this tumour model with respect to more detailed interpretation of the relationship between MRS signature and treatment response.

\section{Conclusions}

In this study we have determined the effects of 17-AAG in a transgenic mouse tumour model that is driven by and addicted to the activated form of the NEU/HER2 oncogene. It therefore represents a good model of ERBB2- 
amplified breast cancer in the clinic. The ERBB2 oncoprotein is highly dependent on HSP90 for its activity and stability. Importantly, we show for the first time that the transgenic mouse mammary tumours driven by NEU/ HER2 show significant regressions in response to 17-AAG treatment. Importantly, this recapitulates the regressions also seen in ERBB2-positive breast cancer patients. Regressions were associated with a decrease in NEU/HER2 oncoprotein expression. The metabolic signature obtained by ${ }^{31} \mathrm{P}$ MRS showed a decrease in choline phospholipid. This finding was essentially similar between solid mammary tumours treated in vivo and the isolated tumour cells treated in culture. The decrease in choline phospholipids is consistent with a reduced malignant potential and suggests a normalisation of the choline phospholipid metabolism. The MRS changes observed in the choline phospholipid metabolites are consistent with inhibition and depletion of oncogenic signal transduction proteins, including NEU/ HER2, and with decreased cell proliferation and tumour growth inhibition. Hence the observed MRS signature provides a basis for the potential use of MRS as a preclinical and clinical biomarker tool for investigating the antitumour activity of HSP90 inhibitors, particularly in the context of NEU/HER2/ERBB2-driven breast cancer.

\section{Competing interest}

The Institute of Cancer Research has a commercial interest in HSP9O inhibitors. PW, Y-L C, NMSA, SYS, MOL and UB are employees of The Institute of Cancer Research which has a rewards to inventors scheme. Work on the discovery of HSP90 inhibitors in PW's group was funded by Vernalis and HSP90 inhibitors were licensed to Vernalis and Novartis.

\section{Acknowledgements}

This work was supported by Cancer Research UK grant nos C12/A5095, C12/ A5096, C1060/A808, C309/A2187 and C309/A8274. P Workman is a Cancer Research UK Life Fellow.

The authors would like to thank Mrs G Vigayaraghavan and Dr I Titley for help with flow cytometry analyses and Mr. Gary Box for the establishment of the MMTV-NEU-NT tumour cell line. The ICR authors acknowledge National Health Service funding to the NIHR Biomedical Research Centre.

\section{Author details \\ ${ }^{1}$ Cancer Research UK Cambridge Research Institute, Li Ka Shing Centre, Robinson Way, Cambridge CB2 ORE, UK. ${ }^{2}$ Cancer Research UK and EPSRC Cancer Imaging Centre, The Institute of Cancer Research and The Royal Marsden NHS Foundation Trust, Sutton, Surrey SM2 5PT, UK. ${ }^{3}$ Cancer Research UK Centre for Cancer Therapeutics, The Institute for Cancer Research, Sutton, Surrey SM2 5NG, UK.}

\section{Authors' contributions}

LR performed the in vivo experiments, analysed the data, coordinated the study and co-drafted the manuscript; YLC performed the MRS of the tissue extracts; NS and LEJ acquired all the isolated cell data; SS and UB did western blots on the tissue extracts; ML provided useful discussion; MS and JRG participated in the original conception of the study, in the interpretation of the results, and co-drafted the manuscript, PW participated in the original conception of the study, supervised it and co-drafted the manuscript. All authors read and approved the final manuscript.

Received: 13 April 2012 Accepted: 23 May 2012

Published: 23 May 2012

\section{References}

1. Modi S, Stopeck AT, Gordon MS, Mendelson D, Solit DB, Bagatell R, Ma W, Wheler J, Rosen N, Norton L, Cropp GF, Johnson RG, Hannah AL, Hudis CA Combination of trastuzumab and tanespimycin (17-AAG, KOS-953) is safe and active in trastuzumab-refractory HER-2-overexpressing breast cancer: A Phase I dose-escalation study. J Clin Oncol 2007, 25:5410-5417.

2. Modi S, Stopeck AT, Linden HM, Solit DB, Chandarlapaty S, Rosen N, D'Andrea G, Dickler MN, Moynahan ME, Sugarman S, Ma W, Patil S, Norton L, Hannah AL, Hudis C: HSP90 Inhibition is Effective in Breast Cancer: A Phase 2 Trial of Tanespimycin (17AAG) plus Trastuzumab in Patients with HER2-Positive Metastatic Breast Cancer Progressing on Trastuzumab. Clin Cancer Res 2011, 17:5132-5139.

3. Arteaga $\mathrm{CL}$ : Why Is This Effective HSP90 Inhibitor Not Being Developed in HER2+ Breast Cancer? Clin Cancer Res 2011, 17:4919-4921.

4. Slamon DJ, Clarke GM, Wong SG, Levin WJ, Ullrich A, McGuire WL: Human breast cancer: correlation of relapse and survival with amplification of the HER2/neu oncogene. Science 1987, 235:177-182.

5. Montemurro F, Donadio M, Clavarezza M, Redana S, Jacomuzzi ME, Valabrega G, Danese S, Vietti-Ramus G, Durando A, Venturini M, Aglietta M: Outcome of patients with HER2-positive advanced breast cancer progressing during trastuzumab-based therapy. Oncologist 2006, 11:318324.

6. Sharp SY, Boxall K, Rowlands M, Prodromou C, Roe SM, Maloney A, Powers M, Clarke PA, Box G, Sanderson S, Patterson L, Matthews TP, Cheung KM, Ball K, Hayes A, Raynaud F, Marais R, Pearl L, Eccles S, Aheme W, McDonald E, Workman P: In vitro biological characterization of a novel, synthetic diaryl pyrazole resorcinol class of heat shock protein 90 inhibitors. Cancer Res 2007, 67:2206-2216.

7. Neckers L, Workman P: HSP90 molecular chaperone inhibitors: are we there yet? Clin Cancer Res 2012, 18(1):64-76.

8. Basso A, Solit D, Munster P, Rosen N: Ansamycin antibiotics inhibit Akt activation and cyclin $D$ expression in breast cancer cells that over express HER2. Oncogene 2002, 21:1159-1166.

9. Pearl LH, Prodromou C, Workman P: The HSP90 molecular chaperone: an open and shut case for treatment. Biochem J 2008, 410:439-453.

10. Workman P, Maloney A: Hsp90 as a new therapeutic target for cancer therapy: the story unfolds. Expert Opin Biol Ther 2002, 2:3-24.

11. Travers J, Sharp S, Workman P: HSP90 inhibition: two-pronged exploitation of cancer dependencies. Drug Discov Today 2012, 17(5-6):242252. Epub 2011 Dec 30

12. Workman $P$, Burrows F, Neckers $L$, Rosen N: Drugging the cancer chaperone HSP90. Ann N Y Acad Sci 2007, 1113:202-216.

13. Kamal A, Thao L, Sensintaffar J, Zhang L, Boehm MF, Fritz LC, Burrows FJ: A high-affinity conformation of Hsp90 confers tumour selectivity on Hsp90 inhibitors. Nature 2003, 425:357-359.

14. Whitesell L, Lindquist S: HSP90 and the chaperoning of cancer. Nat Rev Cancer 2005, 5:761-772.

15. Ursini-Siegel J, Schade B, Cardiff RD, Muller WJ: Insights from transgenic mouse models of ERBB2-induced breast cancer. Nat Rev Cancer 2007, 7:389-397.

16. Muller WJ, Sinn E, Pattengale PK, Wallace R, Leder P: Single-step induction of mammary adenocarcinoma in transgenic mice bearing the activated c-neu oncogene. Cell 1988, 54:105-115.

17. Workman P, Aboagye EO, Chung Y-L, Griffiths JR, Hart R, Leach MO, Maxwell RJ, McSheehy PMJ, Price PM, Zweit J: Minimally invasive pharmacokinetic and pharmacodynamic technologies in hypothesis-testing clinical trials of innovative therapies. J Natl Cancer Inst 2006, 98:580-598.

18. Smith-Jones PM, Solit D, Afroze F, Rosen N, Larson M: Early tumour response to Hsp90 therapy using HER2 PET: comparison with ${ }^{18} \mathrm{~F}$ - FDG PET. J NuCl Med 2006, 47:793-796.

19. Wilmann JK, van Bruggen N, Dinkelborg LM, Gambhir SS: Molecular imaging in drug development. Nat Rev Drug Discov 2008, 7:591-607.

20. Gillies RJ, Bhujwalla ZM, Evelhoch J, Garwood M, Neeman M, Robinson SP, Sotak $\mathrm{CH}$, Van Der Sanden B: Applications of magnetic resonance in model systems. Tumour Biology and Physiology. Neoplasia 2000, 2:139-151.

21. Evelhoch JL, Gillies RJ, Karczmar GS, Koutcher JA, Maxwell RJ, Nalcioglu O, Raghunand N, Ronen SM, Ross BD, Swartz HM: Applications of magnetic resonance in model systems: Cancer Therapeutics. Neoplasia 2000, 2:152-165.

22. Rodrigues LM, Stubbs M, Robinson SP, Newell B, Mansi J, Griffiths JR: The Cneu mammary carcinoma in oncomice; characterization and monitoring 
response to treatment with herceptin by magnetic resonance methods. MAGMA 2004, 17:260-270.

23. Leach MO, Verrill M, Glaholm J, Smith TA, Colins DJ, Payne GS, Sharp JC, Ronen SM, McCready VR, Powles TJ, Smith IE: Measurements of human breast cancer using magnetic resonance spectroscopy: a review of clinical measurements and a report of localized ${ }^{31} \mathrm{P}$ measurements of response to treatment. NMR Biomed 1998, 11:314-340.

24. Griffiths JR, Tate AR, Howe FA, Stubbs M: Magnetic resonance spectroscopy of cancer-practicalities of multi-cancer trials and early results in non-Hodgkins lymphoma. Eur J Cancer 2002, 38:2085-2093.

25. Chung YL, Griffiths JR: Using metabolomics to monitor anticancer drugs. Ernst Schering Found Symp Proc 2007, 4:55-78

26. Chung Y-L, Troy H, Banerji U, Jackson LE, Walton MI, Stubbs M, Griffiths JR, Judson IR, Leach MO, Workman P, Ronen SM: Magnetic Resonance Spectroscopic Pharmacodynamic markers of Hsp90 inhibitor, 17-allylamino-17-demethoxygeldanamycin (17-AAG) in human colon cancer models. J Natl Cancer Inst 2003, 95:1624-1633.

27. Brandes $\mathrm{AH}$, Ward CS, Ronen SM: 17-allyamino-17demethoxygeldanamycin treatment results in a magnetic resonance spectroscopy-detectable elevation in choline containing metabolites associated with increased expression of choline transporter SLC44A1 and phospholipase A2. Breast Cancer Res 2010, 12:R84.

28. Le Carl H, Lupu M, Kotedia K, Rosen N, Solit D, Koutcher JA: Proton MRS detects Metabolic Changes in Hormone Sensitive and Resistant Human Prostate Cancer Model CWR22 and CWR22r. Magn Reson Med 2009, 62(5):1112-1119.

29. Workman $P$, et al: UKCCCR Guidelines for the welfare of animals in experimental neoplasia. Br J Cancer 1998, 77(1):1-10.

30. Ordidge RJ, Connelly A, Lohman JAB: Image selected in vivo spectroscopy (ISIS). A new technique for spatially selective NMR spectroscopy. J Magn Reson 1986, 66:283-294.

31. Van der Veen JWC, de Beer R, Luyten PR, van Ormondt D: Accurate quantification of in vivo ${ }^{31} \mathrm{P}$ NMR signals using the variable projection method and prior knowledge. Magn Reson Med 1988, 6:92-98.

32. Sharp SY, Kelland LR, Valenti MR, Brunton LA, Hobbs S, Workman P: Establishment of an isogenic human colon tumour model for NQO1 gene expression: Application to investigate the role of DT- diaphorase in bioreductive drug activation in vitro and in vivo. Mol Pharmacol 2000, 58:1146-1155.

33. Hotz MA, Gong J, Traganos F, Darzynkiewicz Z: Flow Cytometric Detection of Apoptosis: Comparison of the Assays of In Situ DNA Degradation and Chromatin Changes. Cytometry 1994, 15:237-244.

34. Al-Saffar NMS, Troy H, RamirezdeMolina A, Jackson LE, Madhu B, Griffiths JR, Leach MO, Workman P, Lacal JC, Judson IR, Chung YL: Noninvasive magnetic resonance spectroscopic pharmacodynamic markers of the choline kinase inhibitor MN58b in human carcinoma models. Cancer Res 2006, 66(1):427-434.

35. Tyagi RK, Azrad A, Degani H, Salomon Y: Simultaneous extraction of cellular lipids and water-soluble metabolites: Evaluation by NMR spectroscopy. Magn Reson Med 1996, 35:194-200.

36. Sharp SY, Prodromou C, Boxall K, Powers MV, Holmes JL, Box G, Matthews TP, Cheung KM, Kalusa A, James K, Hayes A, Hardcastle A, Dymock B, Brough PA, Barril X, Cansfield JE, Wright L, Surgenor A, Foloppe N, Hubbard RE, Aherne W, Pearl L, Jones K, McDonald E, Raynaud F, Eccles S, Drysdale M, Workman P: Inhibition of the heat shock protein 90 molecular chaperone in vitro and in vivo by novel, synthetic, potent resorcinylic pyrazole/isoxazole amide analogues. Mol Cancer Ther 2007. 6(4):1198-1211.

37. Banerji U, O'Donnell A, Scurr M, Pacey S, Stapleton S, Asad Y, Simmons L, Maloney A, Raynaud F, Campbell M, Walton M, Lakhani S, Kaye S, Workman $P$, Judson I: Phase I pharmacokinetic and pharmacodynamic study of 17-Allylamino, 17-Demethoxygeldanamycin in patients with advanced malignancies. J Clin Oncol 2005, 23:4152-4161.

38. Banerji U, Walton M, Raynaud F, Grimshaw R, Kelland L, Valenti M, Judson I, Workman P: Pharmacokinetic-pharmacodynamic relationships for the heat shock protein 90 molecular chaperone inhibitor 17-allylamino, 17-demethoxygeldanamycin in human ovarian cancer xenograft models. Clin Cancer Res 2005, 11:7023-7032.

39. Eaton JD, Perry MJA, Todryk SM, Mazucco RA, Kirby RS, Griffiths JR, Dalgleish AG: Genetic prodrug activation therapy (GPAT) in two rat prostate models generates an immune bystander effect and can be monitored by magnetic resonance techniques. Gene Ther 2001, 8:557-567.

40. Clarke PA, Hostein I, Banerji U, Di Stefano F, Maloney A, Walton M, Judson I, Workman P: Gene expression profiling of human colon cancer cells following inhibition of signal transduction by 17-allylamino-17 -demthoxygeldanamycin, an inhibitor of the hsp90 molecular chaperone. Oncogene 2000, 19:4125-4133.

41. Negendank W: Studies of human tumours by MRS: a review. NMR Biomed 1992, 5:303-324

42. Beloueche-Babari M, Arunan V, Jackson LE, Perusinghe N, Sharp SY, Workman P, Leach MO: Modulation of melanoma cell phospholipid metabolism in response to heat shock protein 90 inhibition. Oncotarget 2010, 1(3):185-197

43. Sharpless NE, DePinho RA: The mighty mouse: genetically engineered mouse models in cancer drug development. Nat Rev Drug Discov 2006 5:741-754

44. Olive K, Tuveson D: The use of targeted mouse models for preclinical testing of novel cancer therapeutics. Clin Cancer Res 2006, 12:5277-5287.

45. Field SB, Needham S, Burney IA, Maxwell RJ, Coggle JE, Griffiths JR: Differences in vascular response between primary and transplanted tumours. Br J Cancer 1991, 63:723-726.

doi:10.1186/1756-0500-5-250

Cite this article as: Rodrigues et al.: Effects of HSP90 inhibitor 17allylamino-17-demethoxygeldanamycin (17-AAG) on NEU/HER2 overexpressing mammary tumours in MMTV-NEU-NT mice monitored by Magnetic Resonance Spectroscopy. BMC Research Notes 2012 5:250.

\section{Submit your next manuscript to BioMed Central and take full advantage of:}

- Convenient online submission

- Thorough peer review

- No space constraints or color figure charges

- Immediate publication on acceptance

- Inclusion in PubMed, CAS, Scopus and Google Scholar

- Research which is freely available for redistribution 